the long and narrow patent ductus arteriosus, was diagnosed and dealt with. Dysphagia owing to right aortic arch with left ligamentum is known to present late, unlike double aortic arch, which usually presents early. ${ }^{2,4}$ We were surprised by the relative ease with which the arch could be mobilized and translocated anteriorly from behind the esophagus. The LSCA, which was already stenosed, was sacrificed to achieve a tension-free anastomosis.

During the development of normal aortic arches, there is dissolution of the right sixth aortic arch and of the dorsal aorta distal to the right subclavian artery. The right aortic arch with mirror-image branching is almost always associated with an intracardiac defect. A large percentage of patients with right aortic arch and retroesophageal LSCA do not have intracardiac anomalies. ${ }^{4}$ The pathologic anatomy in this patient could be explained by the dissolution of the left fourth aortic arch with the presence of a left dorsal aorta. The "ductal theory" of development of coarctation could explain the development of this condition in the absence of an intracardiac anomaly. The ductal tissue migration to the origin of the LSCA and the arch could possibly explain the stenotic origin of the LSCA and the hypoplastic arch. The Kommerell diverticulum is formed by the proximal portion of the left dorsal aorta, the presence of which is an indirect indicator of the presence of ligamentum on that side.

Kommerell diverticulum is known to cause residual tracheoesophageal obstruction in patients with vascular ring. ${ }^{5}$ This could be because of the gradual enlargement of the diverticulum and also because of the tugging effect of the LSCA. It is also known to be prone to aneurysmal and degenerative atherosclerotic changes. ${ }^{6}$ We excluded the diverticulum by using a large Ligaclip ligating clip at its base. The division of the subclavian artery would prevent a slinglike effect, which would predispose to tracheoesophageal compression.

In summary, we believe that median sternotomy is the best approach in the management of coarctation of the circumflex aorta. It permits extensive mobilization of the arch and arch vessels on either side of the esophagus. The mobilized arch can easily be translocated anteriorly to achieve native tissue-tissue anastomosis. It also allows management of vascular ring and Kommerell diverticulum. The presence of a vascular ring may be difficult to diagnose in the absence of symptoms, and it has the potential to cause late-onset symptoms of predominantly esophageal compression. This approach also permits correction of any additional intracardiac defect.

\section{References}

1. Song J, Kim WH, Kim H, Koh J, Kwak JG, Kim KB, et al. Repair of coarctation in right circumflex retroesophageal arch. Ann Thorac Surg. 2009;87:307-9.

2. Gil-Jaurena JM, Murtra M, Gonçalves A, Miró L. Aortic coarctation, vascular ring, and right aortic arch with aberrant subclavian artery. Ann Thorac Surg. 2002;73:1640-2.

3. Ahluwalia GS, Rashid AG, Griselli M, Szczeklik M, Rigby ML, Mohiaddin RH, et al Hypoplastic circumflex retroesophageal right-sided cervical aortic arch with unusual vascular arrangement and severe coarctation. Ann Thorac Surg. 2007;84:1014-6.

4. Allen HD, Driscoll DJ, Shaddy RE, Feltes TF. Aortic arch anomalies. In: Moss and Adams' heart disease in infants, children and adolescents: including the fetus and young adults. 7th ed, vol I, sect VII, chap 36. Philadelphia: Lippincott Williams and Wilkins; 2008. p. 731-56.

5. Backer CL, Hillman N, Mavroudis C, Holinger LD. Resection of Kommerell's diverticulum and left subclavian artery transfer for recurrent symptoms after vascular ring division. Eur J Cardiothorac Surg. 2002;22:64-9.

6. Kouchokous N, Massetti P. Aberrant subclavian artery and Kommerell aneurysm: surgical treatment with a standard approach. J Thorac Cardiovasc Surg. 2007;133: 888-92.

\title{
Successful thoracoscopic surgery for intractable pneumothorax after pneumonectomy under local and epidural anesthesia
}

\author{
Masafumi Noda, MD, Yoshinori Okada, MD, Sumiko Maeda, MD, and Takashi Kondo, MD, Sendai, Japan
}

\footnotetext{
From the Department of Thoracic Surgery, Institute of Development, Aging and Cancer, Tohoku University, Sendai, Japan.

Disclosures: Authors have nothing to disclose with regard to commercial support.

Received for publication Aug 24, 2010; revisions received Sept 14, 2010; accepted for publication Oct 17, 2010; available ahead of print Dec 17, 2010.

Address for reprints: Masafumi Noda, MD, Department of Thoracic Surgery, Institute of Development, Aging and Cancer, Tohoku University, 4-1 Seiryo-machi, Aobaku Sendai, 980-8575 Japan (E-mail: noda.m@idac.tohoku.ac.jp).

J Thorac Cardiovasc Surg 2011;141:1545-7

$0022-5223 / \$ 36.00$

Copyright (c) 2011 by The American Association for Thoracic Surgery

doi:10.1016/j.jtcvs.2010.10.021
}

Management of pneumothorax in patients with limited pulmonary function of the contralateral lung is complicated. Among these situations, pneumothorax after pneumonectomy is potentially lethal and its treatment poses a significant risk. ${ }^{1}$ We report a case of intractable right pneumothorax after left pneumonectomy, successfully treated by video-assisted thoracic surgery (VATS) under local and epidural anesthesia.

\section{CLINICAL SUMMARY}

A 74-year-old male patient underwent left pneumonectomy and mediastinal lymph node dissection for squamous 


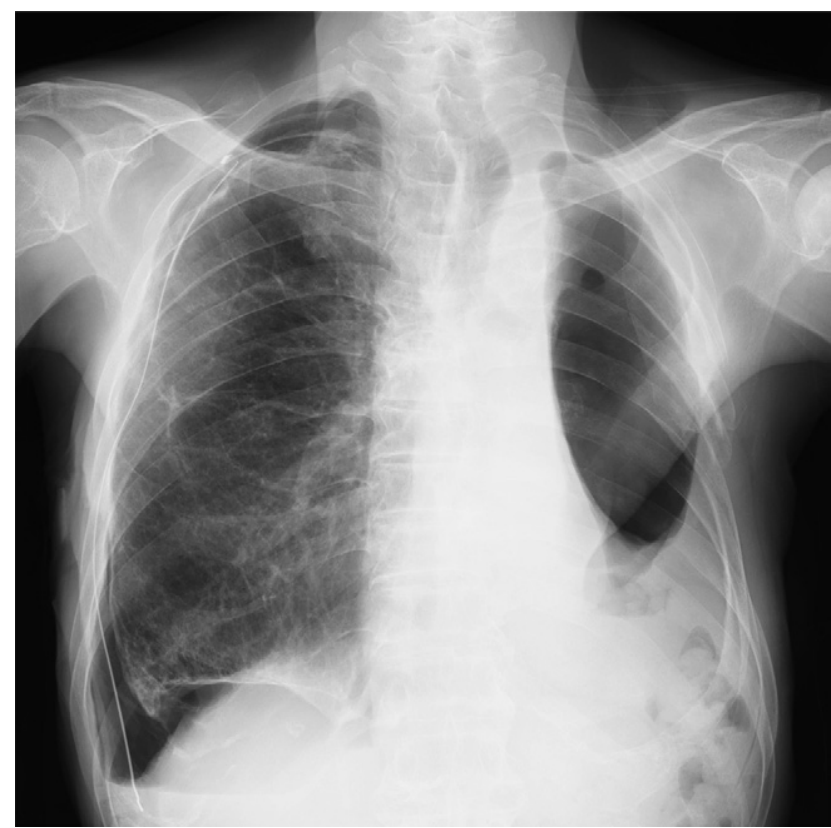

FIGURE 1. Chest $x$-ray film showing a right pneumothorax after left pneumonectomy and open thoracotomy.

cell carcinoma of the lung at another hospital. Pathologic stage was T2 N0 M0. Five months later, a metastasis of the lung cancer to the pineal gland was treated by $60 \mathrm{~Gy}$ of radiotherapy. In the meanwhile, an additional metastasis to the skin of the left chest wall was resected. The operation, however, was complicated by a subcutaneous abscess extending to pyothorax requiring open drainage thoracotomy. One month later, a right pneumothorax developed, necessitating placement of a drainage tube (Figure 1). Pleurodesis with OK-432 has been reported to be efficacious for controlling malignant pleural effusions. ${ }^{2}$ Pleurodesis with autologous blood and OK-432 was attempted but was unsuccessful. Eventually, the patient was transferred to our hospital. Chest computed tomography showed diffuse emphysema and apical multiple bullae in the right lung. Because of severe air leakage and incomplete re-expansion of the right lung, we abandoned additional pleurodesis and chose VATS with local and epidural anesthesia because of his poor general condition. A thoracic epidural catheter was inserted at the T4 level on the day before the operation in preparation for the use of extracorporeal membrane oxygenation (ECMO) in case surgery with the patient awake was unsuccessful. The epidural was placed a day early to reduce the risk of epidural hematoma in the event that ECMO was required at the time of the operation. Continuous infusion of $0.2 \%$ ropivacaine was started. The patient maintained spontaneous breathing throughout the operation and was supplied with oxygen to keep functional oxygen saturation greater than $94 \%$. The patient was placed in the left lateral decubitus position. After local anesthesia

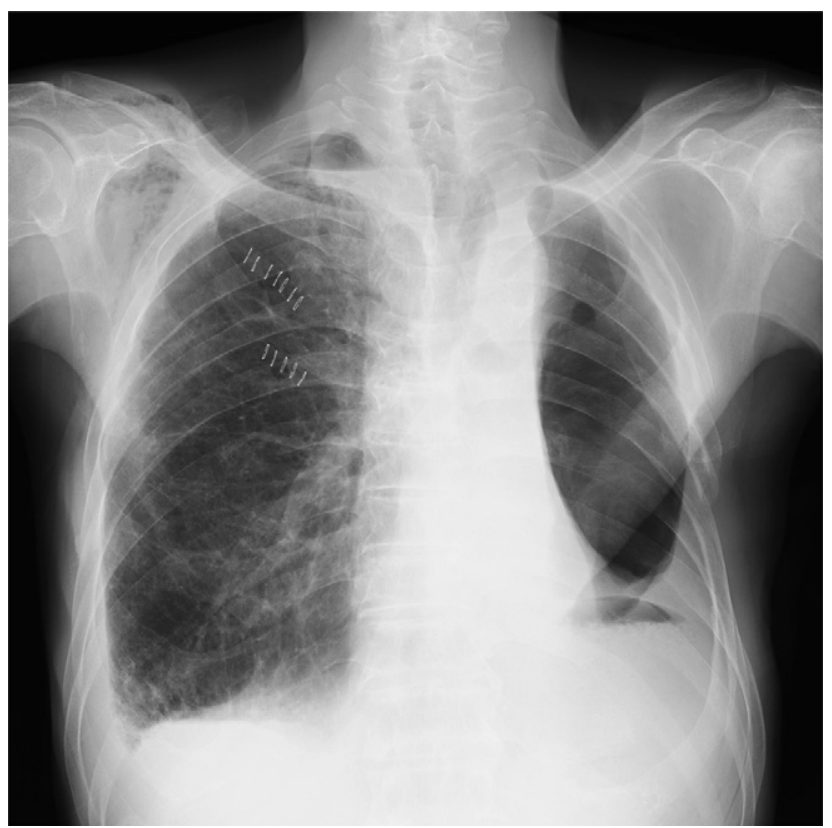

FIGURE 2. Chest x-ray film showing complete pulmonary re-expansion after video-assisted thoracic surgery under local and epidural anesthesia.

with $1 \%$ lidocaine, a 5 -mm port was inserted in the third intercostal space at the midclavicular line. A 5-mm flexible scope was introduced. Although focal pleural adhesion was seen in the upper lobe, the partially deflated lung provided a satisfactory endoscopic view. Whenever desaturation was recorded, the lung was temporarily re-expanded by sucking the air in the pleural cavity through the chest drainage tube. Another small skin incision was made in the second intercostal space at the anterior axillary line. A ruptured bulla in the apex was found and resected with an Endo-GIA 60-3.5 (Tyco Healthcare Japan, Tokyo, Japan). Pieces of polyglycolic acid sheet were affixed around the staple line and fibrin glue was sprayed. A chest drainage tube was inserted and placed on suction. The lowest functional oxygen saturation during the operation was $95 \%$. A chest x-ray film after the operation showed good reexpansion of the right lung and the postoperative course was uneventful. The chest drainage tube was removed on day 1 after the operation (Figure 2). The patient was discharged on day 4 and no recurrence of pneumothorax has been observed at 4 months after the operation.

\section{DISCUSSION}

Surgical intervention for pneumothorax after pneumonectomy is quite challenging. Traditional surgical treatment consists of bullectomy and pleurectomy with intermittent apnea under general anesthesia and mechanical ventilation, which possesses the disadvantages of perioperative barotraumas and postoperative respiratory dysfunction associated with large thoracotomy. ${ }^{3}$ Therefore, several authors 
have reported minimally invasive VATS using ECMO. ${ }^{4,5}$ The use of ECMO, however, has a potential problem with bleeding, especially when pleural adhesion exists. In the present case, we selected VATS under local and epidural anesthesia with preparation of ECMO, expecting less bleeding during the operation and early recovery after the operation. The procedure was well tolerated and the air leakage was completely controlled. The patient was discharged on day 4 after the operation.

VATS procedures under local and epidural anesthesia have been reported in patients with spontaneous pnemothorax ${ }^{6}$ and secondary pneumothorax after lung transplantation. ${ }^{7}$ In a small randomized study, Pompeo and collegues $^{8}$ reported that awake VATS bullectomy with pleural abrasion for spontaneous pneumothorax was feasible and provided equivalent outcome to procedures with the patient under general anesthesia. Thoracoscopic operations with the patient awake, however, have limitations. First, effective epidural anesthesia is indispensable and general anesthesia has to be induced when effective analgesia cannot be obtained. Second, total lung collapse cannot be obtained, especially in patients with limited contralateral pulmonary function, and thus lesions close to the hilum would not be adequately treated. Bearing these limitations in mind, we conclude that VATS under local and epidural anesthesia can be applicable to selected patients with pneumothorax after pneumonectomy and is especially useful in those whose general condition has deteriorated.

\section{References}

1. Kopec SE, Irwin RS, Umali-Torres CB, Balikian JP, Conlan AA. The postpneumonectomy state. Chest. 1998;114:1158-84.

2. Luh KT, Yang PC, Kuo SH, Chang DB, Yu CJ, Lee LN. Comparison of OK-432 and mitomycin $\mathrm{C}$ pleurodesis for malignant pleural effusion caused by lung cancer. A randomized trial. Cancer. 1992;69:674-9.

3. Waller DA, Forty J, Morritt GN. Video-assisted thoracoscopic surgery versus thoracotomy for spontaneous pneumothorax. Ann Thorac Surg. 1994;58: 372-6.

4. Oey IF, Peek GJ, Firmin RK, Waller DA. Post-pneumonectomy video-assisted thoracoscopic bullectomy using extra-corporeal membrane oxygenation. Eur $J$ Cardiothorac Surg. 2001;20:874-6.

5. Birdas TJ, Beckart DH, Keenan RJ. Contralateral spontaneous pneumothorax after pneumonectomy: thoracoscopic management with cardiopulmonary bypass. Interact Cardiovasc Thorac Surg. 2005;4:27-9.

6. Nezu K, Kushibe K, Tojo T, Takahama M, Kitamura S. Thoracoscopic wedge resection of blebs under local anesthesia with sedation for treatment of a spontaneous pneumothorax. Chest. 1997;111:230-5.

7. Sugimoto S, Date H, Sugimoto R, Okazaki M, Aoe M, Sano Y, et al. Thoracoscopic operation with local and epidural anesthesia in the treatment of pneumothorax after lung transplantation. J Thorac Cardiovasc Surg. 2005;130: 1219-20.

8. Pompeo E, Tacconi F, Mineo D, Mineo TC. The role of awake video-assisted thoracoscopic surgery in spontaneous pneumothorax. I Thorac Cardiovasc Surg. 2007;133:786-90.

\title{
Arterial switch operation in children with interrupted aortic arch: Long-term outcomes
}

\author{
Tyson A. Fricke, BMedSci, Christian Brizard, MS, MD, Yves d'Udekem, MD, PhD, and
}

Igor E. Konstantinov, $\mathrm{MD}, \mathrm{PhD}$, Melbourne, Australia

Transposition of the great arteries associated with interrupted aortic arch (TGA-IAA) is a very uncommon anomaly. Only approximately $6 \%$ to $10 \%$ of children with IAA have $\mathrm{TGA}^{1,2}$ and surgical repair in these patients is com-

\footnotetext{
From Cardiac Surgery Unit, Royal Children's Hospital, Department of Paediatrics, University of Melbourne and Murdoch Children's Research Institute, Melbourne, Australia.

Disclosures: Authors have nothing to disclose with regard to commercial support.

Received for publication July 7, 2010; revisions received Aug 24, 2010; accepted for publication Oct 17, 2010; available ahead of print Dec 20, 2010.

Address for reprints: Igor Konstantinov, MD, PhD, Royal Children's Hospital, Flemington Road, Parkville, VIC 6009, Australia, Tel: 6139345 5200; Fax: 613 93456386 (E-mail: igor.konstantinov@rch.org.au).

J Thorac Cardiovasc Surg 2011;141:1547-8 $0022-5223 / \$ 36.00$

Crown Copyright (C) 2011 Published by Elsevier Inc. on behalf of The American Association for Thoracic Surgery

doi:10.1016/j.jtcvs.2010.10.024
}

plex. Herein we report the long-term outcomes of 5 patients operated on for TGA-IAA at The Royal Children's Hospital at a mean 14.3 years after repair.

\section{CLINICAL SUMMARY}

The study was approved by a Research Ethics Board of Royal Children's Hospital. Between May 1983 and January 2009, 720 patients underwent an arterial switch operation (ASO) for TGA at the Royal Children's Hospital in Melbourne. Biventricular repair was done in $710(99 \%)$ patients. Of these 710 patients, $5(0.7 \%)$ had TGA-IAA (Table 1). Four of the 5 had IAA type A and 1 had IAA type B. ${ }^{3}$ The 5 patients were operated on at a median of 8 days of age (range, 1-118 days) and at a median weight of $3.44 \mathrm{~kg}$ (range, $3.1-4.76 \mathrm{~kg}$ ). Four patients had singlestage repair of TGA-IAA, and 1 had a staged approach. End-to-side arch repair was performed in 4 patients from 